\title{
Contribution of insurance data to cost assessment of coastal flood damage to residential buildings: insights gained from Johanna (2008) and Xynthia (2010) storm events
}

\author{
C. André ${ }^{1,2}$, D. Monfort ${ }^{2}$, M. Bouzit ${ }^{2}$, and C. Vinchon ${ }^{2}$ \\ ${ }^{1}$ LETG-Brest Géomer, UMR6554 CNRS, University of Western Brittany, European Institute for Marine Sciences, \\ Place Nicolas Copernic, 29280 Plouzané, France \\ ${ }^{2}$ BRGM, 3 avenue Claude Guillemin, BP 36009, 45060 Orléans Cedex 2, France
}

Correspondence to: C. André (camille.andre@ univ-brest.fr, camilleg.andre@ gmail.com)

Received: 5 January 2013 - Published in Nat. Hazards Earth Syst. Sci. Discuss.: 28 March 2013

Revised: 23 June 2013 - Accepted: 2 July 2013 - Published: 8 August 2013

\begin{abstract}
There are a number of methodological issues involved in assessing damage caused by natural hazards. The first is the lack of data, due to the rarity of events and the widely different circumstances in which they occur. Thus, historical data, albeit scarce, should not be neglected when seeking to build ex-ante risk management models. This article analyses the input of insurance data for two recent severe coastal storm events, to examine what causal relationships may exist between hazard characteristics and the level of damage incurred by residential buildings. To do so, data was collected at two levels: from lists of about 4000 damage records, 358 loss adjustment reports were consulted, constituting a detailed damage database. The results show that for flooded residential buildings, over $75 \%$ of reconstruction costs are associated with interior elements, with damage to structural components remaining very localised and negligible. Further analysis revealed a high scatter between costs and water depth, suggesting that uncertainty remains high in drawing up damage functions with insurance data alone. Due to the paper format of the loss adjustment reports, and the lack of harmonisation between their contents, the collection stage called for a considerable amount of work. For future events, establishing a standardised process for archiving damage information could significantly contribute to the production of such empirical damage functions. Nevertheless, complementary sources of data on hazards and asset vulnerability parameters will definitely still be necessary for damage modelling; multivariate approaches, crossing insurance data with external material, should also be investigated more deeply.
\end{abstract}

\section{Introduction}

All over the world, floods represent major threats for people living in river or coastal flood plains (Torterotot, 1993). In the area of natural hazard management policies, and especially in flood risk management, damage assessments in terms of economic losses are gaining importance, in risk and vulnerability management, so as to be able to carry out costbenefit analyses in support of the decision-making process on flood mitigation measures, as well as in financial appraisals and risk prediction required by the insurance and reinsurance sector (Merz et al., 2010). While many studies have been prepared on river flooding damage assessment, coastal flooding events had heretofore received less attention, although the impacts of some of these have been devastating (Lequeux and Ciavola, 2012), for example, the "Big Flood" of the Netherlands in 1953 killed 1836 people (Gerritsen, 2005). Hurricanes that affected the US coasts received more documentation than European winter storms, such as Hurricane Katrina, which struck the Gulf of Mexico and in particular the New Orleans city in 2005, with a death toll of over 1700 (FEMA, 2006; Pistrika and Jonkman, 2010). However, the context of northwest Atlantic hurricanes strongly vary to that of the winter storms of Europe, both on hazard and on coastal assets characteristics (wood vs. masonry structures, use of pile foundations, etc.).

There are several approaches to economic damage assessment, according to the different purposes they are intended to serve. Globally, these can be differentiated into ex-ante assessments and ex-post assessments. Ex-ante assessments, i.e. prior to the event, aim to evaluate potential

Published by Copernicus Publications on behalf of the European Geosciences Union. 
economic losses for scenarios having probable hazard characteristics. Ex-post assessments are carried out in the aftermath of the disaster for emergency management or the coordination of early recovery issues, or later, for feedback on experience concerning damage processes and costs (APFM, 2007). Ex-ante assessment models are generally calibrated with damage data from ex-post assessments. However, most economic analysis guidelines mainly address ex-ante assessments, since ex-post assessments are not as well developed.

Furthermore, types of damage are typically differentiated into direct and indirect damages, which may be tangible or intangible (e.g. Parker et al., 1987; Messner et al., 2007; Meyer et al., 2012). Direct damage is induced directly by the physical processes of the hazard (e.g. structural damage to buildings), while indirect ones are induced by the impact of the direct damages (e.g. costs occurring at a longer period of time or a larger spatial scale to the disaster itself). The difference between tangible and intangible damages is that the first can be valuated monetarily (all marketable goods and services), whereas the second have no market values, e.g. loss of life, damage to ecosystems.

The assets exposed to damage are usually classified into types that share common parameters of sensitivity and/or resistance with respect to the involved hazard parameters and characteristics. For data collection purposes, tangible assets are most often subdivided according to economic sectors (e.g. private, industrial, commercial, public) and subsequently into more detailed subclasses (Merz et al., 2010).

For ex-ante damage assessment purposes, a standard approach calls on damage functions, also referred to as stagedamage curves or fragility curves (Messner et al., 2007). These functions define the causal relationship between the intensity of hazard parameters and a level of damage or loss for each class of assets. They can be expressed in terms of absolute values of estimated costs, or in relative damage, i.e. percent of loss of the asset's initial value, provided this value is known. Depending on the precision needed for the assessment and the spatial scale of the analysis, damage functions can be based on land-use category areas (meso- and macroscale) or on individual objects (micro-scale) (Merz et al., 2010). Likewise, damage curves can focus on one or more hazard parameters. For flood damage modelling, the most common hazard parameter used is water depth, but some studies have investigated other parameters, such as flood duration, flow velocity, and non-physical (i.e. chemical or biological) parameters (e.g. Torterotot, 1993; Kelman and Spence; 2004; Kreibich et al., 2009; Pistrika and Jonkman, 2010).

There are two main approaches in developing damage functions: synthetic methods and empirical ones. While synthetic approaches rely on expert judgement (e.g. the MultiColoured Manual method from Penning-Rowsell et al., 2005), empirical approaches use damage data derived from ex-post assessments of actual past events (e.g. the FLEMO damage model from Thieken et al., 2008). Both approaches for developing damage functions present advantages and disadvantages. While the first method appears more theoretical, the second calls for a substantial effort in collecting ex-post damage information, and such datasets are scarce. Public data, such as the French "Gaspar" (for "Gestion Assistée des Procédures Administratives relatives aux Risques naturels et technologiques", which stands for "French database for the management of administrative procedures related to natural and technological risks") database from the Ministry of Environment ${ }^{1}$ (Deboudt, 2010), are in most instances not detailed enough, being too aggregated, and conducting postflood surveys of the affected population is both time- and money-consuming.

Another source of information on damage is the data gathered by insurance companies for damage compensation purposes. However, insurers' data are mostly not accessible due to confidentiality issues; this explains why few studies have developed damage functions from insurance data (e.g. Merz et al., 2004).

In this study, we used ex-post damage datasets from three French insurance companies for storms Johanna (2008) and Xynthia (2010). This paper's objective is to conduct an initial investigation aimed at appraising the construction of an ex-ante coastal flooding damage model based on empirical direct damage functions, which today are absent from the natural hazard literature. Insurance data, by definition, addresses only tangible and mainly direct damages, as intangible and most of the indirect damages are not insured. For this reason, the scope of this study is limited to direct tangible damages, and in particular to residential building damages, which is the type of asset that was the most affected by the Johanna and Xynthia coastal floods.

Since very few studies could use such data, we sought to demonstrate the benefits and limits of using them to explain which kinds of data may be available within the insurance sector, under what form the information is stored, how it can be used for the purposes of processing damage functions, and how collecting and archiving data by insurers could be integrated in a framework liable to improve damage function processing.

The next section briefly presents the case studies, the dataset available and our method of data collection. Section 3 presents the damage assessment results obtained from a macro- (regional or national summary) to a micro-scale (object-based). Building empirical damage functions from these results, with all the associated uncertainties, is discussed in Sect. 4. Section 5 concludes on how to enhance data collection, and the need to complete insurance data with other data sources, especially on involved hazard parameters and on the vulnerability of assets.

1 http://macommune.prim.net/gaspar (last access: December 2012). 


\section{Data and methods}

\subsection{Study area and storms presentation}

Most of the time, coastal flooding is induced by a conjunction of several parameters (Pedreros et al., 2010): (i) the storm depression causes an elevation of the sea surface by inverse barometer effect, (ii) the storm winds generate a modification of the surface currents that causes local water level elevations (wind setup), (iii) the waves generated by the storm, when reaching the coast, beak and also carry water shoreward (wave setup) and can produce local overtopping of dikes (wave runup).

The Johanna storm struck the French Brittany region and southern Great Britain on 10 March 2008 over a $48 \mathrm{~h}$ period, with winds between 130 and $150 \mathrm{~km} \mathrm{~h}^{-1}$ along the coast, an atmospheric depression of $975 \mathrm{hPa}$ over Brittany and particularly high waves measuring up to $13 \mathrm{~m}$ offshore, which caused a coastal storm surge phenomena (Cariolet et al., 2010). Moreover, the storm occurred in conjunction with high spring tides (of a coefficient of 106 at Brest, compared to a maximum of 120 for the highest theoretically possible tide).

The Xynthia storm affected the Spanish and French Atlantic coastal regions on 28 February 2010, with winds up to $160 \mathrm{~km} \mathrm{~h}^{-1}$ and a maximum depression of $970 \mathrm{hPa}$, resulting in an extremely intense storm surge measured up to $1.5 \mathrm{~m}$ at La Rochelle, in conjunction with a tide coefficient of 102 (Bertin et al., 2012).

This led to very high water levels and waves along the coast responsible for coastline erosion and local coastal flooding of several urban areas. Damage was caused by the contact of saltwater with buildings, remaining stagnant for many days in certain areas, or with significant velocities or mechanical shocks from waves in the most exposed places (Pedreros et al., 2010). Due to a high human exposure in lowlying urbanised areas, the Xynthia storm surge led to hugely stronger impacts and killed 41 people in flooded areas (Vinet et al., 2012; Genovese and Przyluski, 2013).

In France, damage from natural disasters (e.g. river and coastal floods, earthquakes, landslides, droughts) are indemnified under the "CatNat" scheme (for "Catastrophes Naturelles"), but which exclude damage caused by storm winds, as well as those due to hail, frost, and snow, considered to be insurable under the conventional system and not included in this regime (Deboudt, 2010). The overall loss due to the Xynthia storm is evaluated at approximately 2.5 billion $€, 1.5$ billion $€$ of which, in direct costs, was supported by insurance and reinsurance companies (FFSA and GEMA, 2011). The present work focused on insured damages (mostly direct damages), that were induced by coastal flooding processes, i.e. under the "CatNat" scheme, and especially on personal lines property damages, i.e. residential building damages, which represents 745 million $€$ and 450 million $€$, respectively.

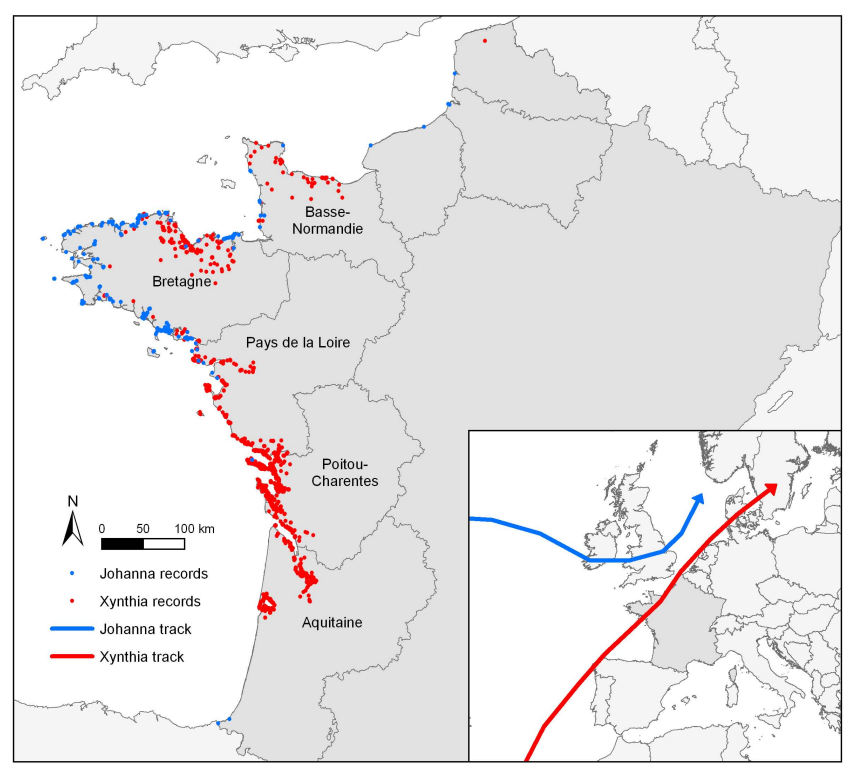

Fig. 1. Map of flood-damage records in the first-level database for the three insurance companies that took part in the study. The resulting dataset is believed to represent around $25 \%$ of the overall insurance market in France.

\subsection{Dataset presentation}

Three significant insurance companies operating on the French market provided access to their compensation datasets, so as to enable an analysis of the damage caused by both events to be performed. The insurers' lists of damage records for both storms contain some basic information on damage: (i) the record references: ID code, localisation of the file in the main office or a local agency; (ii) the damage location: town, zip code, and in most instances the address, or at least the street, where the damage occurred; (iii) the type of insurance policy: type of asset affected, e.g. housing, small or medium-sized enterprise, shop, crops, vehicle, boat; and (iv) the total amount of indemnities paid by the insurer.

These data contain no information on damage processes or on asset characteristics. This key information can only be found in the detailed loss adjustment reports made by experts mandated by insurers after the disaster, which are the source of damage indemnity evaluations.

Those loss adjustment reports, based on an on-site visit by a certified expert, contain useful detailed information for damage analysis, which are, for residential building records: (i) the damage circumstances: when and how the flood occurred and how the building was affected (e.g. structural issues), which provides information about physical processes that caused the damage, such as simple flooding, currents, waves shocks, scouring and undermining, together with the intensity of these processes (mostly water depth and sometimes flood duration); (ii) the terms of the insurance contract, especially the size of the house (e.g. number of storeys and 


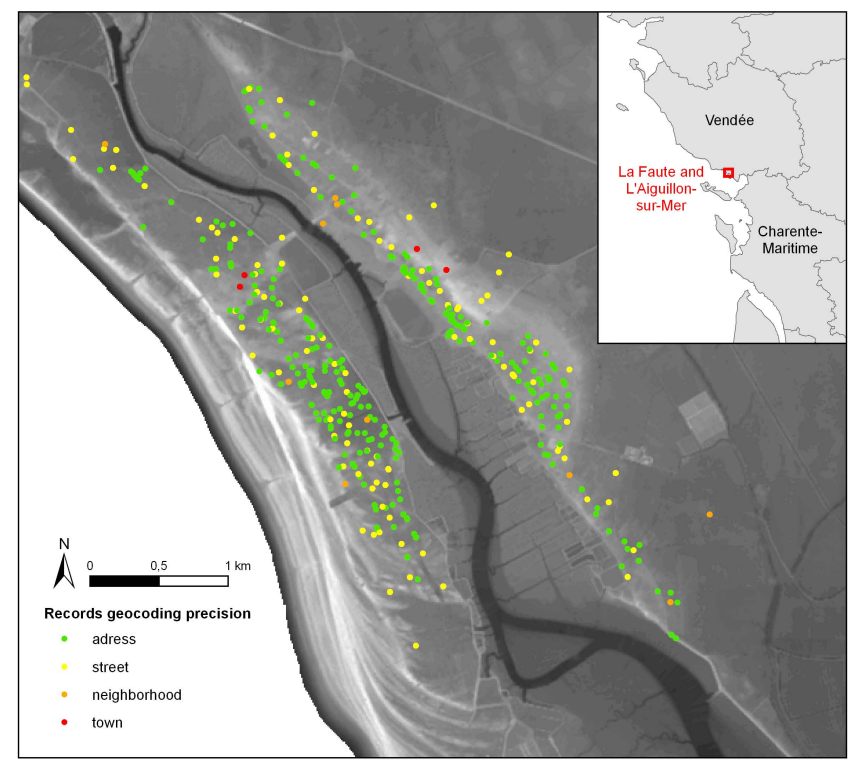

Fig. 2. Map showing the density of damage records for the towns of La Faute-sur-Mer and L'Aiguillon-sur-Mer in the French Vendée Department for the three insurance companies that took part in the study. The resulting dataset is believed to represent around $25 \%$ of the overall insurance market in France. The colour scale indicates the geocoding precision.

main rooms, presence of basement), which provide some elements on the vulnerability of the asset and on its overall value; (iii) a detailed description of damage costs, divided into reconstruction works and damage to building contents (inventory); and (iv) attached documents to the file, sometimes available (e.g. cost estimates and invoices, pictures before and after the damage, testimonies from the insured customer) and all the documents exchanged between the insurer and the customer, which can help understand any particular issues in the damage assessment and indemnification.

\subsection{Data collection method}

The general information from insurers' lists of damage records is what will be termed in this work the "first level of information" of the damage database created. In all, 297 records were available for the Johanna storm, as compared to 4575 for the Xynthia storm. The personal lines property records, i.e. residential building records, is the type of assets that have been the most affected by the two storms (175 and 3956 records, respectively), and so the type for which it is the most relevant to produce a statistical study. Regarding this type of asset, the datasets of the three insurers concerned are believed to represent around $25 \%$ of the overall insured property market in France, on the basis of the FFSA and GEMA report (2011), regarding the Xynthia storm damages.
Amongst these records of residential building damages (mainly detached houses), a sampling of the most interesting ones to investigate was taken from these "first-level" lists, regarding the damage location (town) and the amount of indemnities (records that have a minimum of $10000 €$ damage). So to focus on this selection, the loss adjustment reports were analysed. This detailed information is what will be termed the "second level of information": it allowed a more exhaustive database on damage to be compiled, consisting of 358 records ( 81 of which for Johanna storm and 277 for Xynthia storm).

Loss adjustment reports were most often available in paper format for the three insurance companies that took part in the study. Regarding confidentiality constraints, the collection process took place within the insurance offices, and no copy was made of the original data.

Data compilation was performed using database software, with a suitable data entry form to optimise efficiency. Information was structured into four main blocks: (i) a record references block; (ii) a block containing damage description and indemnification, with a distinction made between the building itself and its contents; (iii) a block containing building specifications (number of storeys, main rooms, surface area, presence of basement, construction materials, etc.), in order to evaluate vulnerability criteria and the asset's overall value; and (iv) a block providing information on hazard parameters, in order to link the type of damage observed to the associated physical processes (i.e. water depth, duration and speed, waves shocks and scour).

It should be pointed out that the precision and completeness of loss adjustment reports are variable and heterogeneous. The description of damage circumstances and hazard information may depend on the experts involved, but also on the customer cooperation, the importance of the damages, etc. For greater precision concerning the damage assessment, information on holders' insurance contracts is also required so as to understand the amount of indemnification. These elements include the value of the deductible, and the mode of compensation of the "outdated state" of the building and contents (i.e. indemnification of "as new" replacement costs or depreciated values above a given threshold). In addition, some specific cases are considered, such as those of unconformity of the customer's declaration (re: surface area, number of main rooms, etc.), in which only a fraction of the damage is compensated, or cases where the accessory structures to the main building are included or not in the contract coverage (e.g. outdoor damage such as that to enclosing walls or fences and gardens).

In order to visualise the impact area of the events and to conduct a spatial analysis, the datasets of both levels were georeferenced in GIS software using the addresses of the 
Table 1. Number of records, mean indemnities $(\overline{\mathrm{X}})$ and standard error of the mean (SEM) per lines of business for Johanna and Xynthia storms, for the three insurance companies that took part in the study. The resulting dataset is believed to represent around $25 \%$ of the overall insurance market in France.

\begin{tabular}{lrrrrrr}
\hline & $\begin{array}{r}\text { Johanna } \\
\text { No. Records }\end{array}$ & $\bar{X}(€)$ & SEM $(€)$ & $\begin{array}{r}\text { Xynthia } \\
\text { No. Records }\end{array}$ & $\bar{X}(€)$ & SEM $(€)$ \\
\hline Personal lines property & 175 & 7128 & 1510 & 3956 & 26622 & 768 \\
Commercial lines & 56 & 43537 & 1636 & 350 & 47178 & 9948 \\
Agricultural sector & 12 & 4637 & 1820 & 139 & 27452 & 466 \\
Motor vehicles & 19 & 4674 & 862 & 120 & 7834 & 529 \\
Yachting & 35 & 3044 & 540 & 10 & 4139 & 2439 \\
\hline Total & 297 & 13254 & 3303 & 4575 & 27677 & 1024 \\
\hline
\end{tabular}

damages and a geocoding tool ${ }^{2}$ based on Google Maps API ( and TeleAtlas data ${ }^{\circledR}$.

\section{Results}

\subsection{First level of information}

The geographic distribution of damage records for the two events is shown in Fig. 1, localising the events at the regional scale. Figure 2 depicts the distribution of damage records corresponding to the Xynthia storm for the municipalities of La Faute-sur-Mer and L'Aiguillon-sur-Mer (Vendée Department). When the precise addresses were not available, the damage records were plotted at the street level, the neighbourhood, or by default only at the town level.

From the first level of information, the damage record lists contain all the records from the three insurance companies that allowed statistics to be computed about the comprehensive impact of the two storms. Table 1 shows the number of flood-related records and the mean cost of damage according to economic sectors for each event. About personal lines property damages, the mean per-record cost was about $7100 €$ for the Johanna storm, and it amounted to about $26600 €$ per record for the Xynthia storm. This value seems realistic in the light of the value of $23700 €$ for the overall insurance market from the FFSA and GEMA report (2011). The difference in unit costs between the two events can be explained by the difference in hazard intensity, and by the difference in the asset's exposure between the two impacted regions. For example, Table 1 shows that commercial sector mean costs are close to each other for the two storms, whereas agricultural sector damages are almost six times higher for Xynthia compared to Johanna ones. This can be explained by the greater flood duration of Xynthia, but also by the fact that farmlands are larger in the Vendean region than in Brittany. The statistics also show the important variation of the costs, which complicates interpretation

\footnotetext{
${ }^{2}$ http://www.batchgeocodeur.mapjmz.com (last access: December 2012).
}

at this scale. For the personal lines property damages, the most important media coverage of Xynthia event could also explain a part of the differences between the two storms; Thourot (2012) says that after events that caused deaths, which are largely broadcasted, the loss adjustment conditions and controls are frequently softened.

Figure 3 shows the distribution of the costs for each coastal town where cumulated indemnities reached 1 million $€$. As outlined above, the two towns that experienced the highest total costs are La Faute-sur-Mer and L'Aiguillon-sur-Mer, but they do not have the highest mean indemnities. The affected towns display a wide range of mean and median costs, which may be linked to local hazard parameters and intensity, but also to varying characteristics and vulnerability degrees of the concerned assets. For instance, towns can have different proportions of primary/secondary residences, and inhabitants can have different levels of incomes. As an example, the mean family wage was about $19800 €$ for the town of L'Aiguillon-sur-Mer in $2010^{3}$, which has a relatively low mean indemnity. On the contrary, the towns of Les Portes-enRé and Loix, which have relatively high mean indemnities, also have a higher mean family wage of about $28200 €$ and $26600 €$, respectively.

\subsection{Second level of information}

For the second level of information, the detailed database compiled contains a smaller number of damage records, but it did allow the damages processes and costs to be analysed in greater detail and a damage typology to be developed. Damages are classified according to three principal types: (i) damages to main buildings, with a difference made for records regarding main rooms and records for garages or basements damages only; (ii) damages to accessory buildings, such as outhouses, garden sheds, mobile homes or bungalows; and (iii) damages to outdoor elements, such as plot fences and gates, retaining walls, terraces and swimming pools. This typology can be used to separate costs into homogeneous

\footnotetext{
${ }^{3}$ French Ministry of Taxes, http://www.impots.gouv.fr (last access: December 2012).
} 


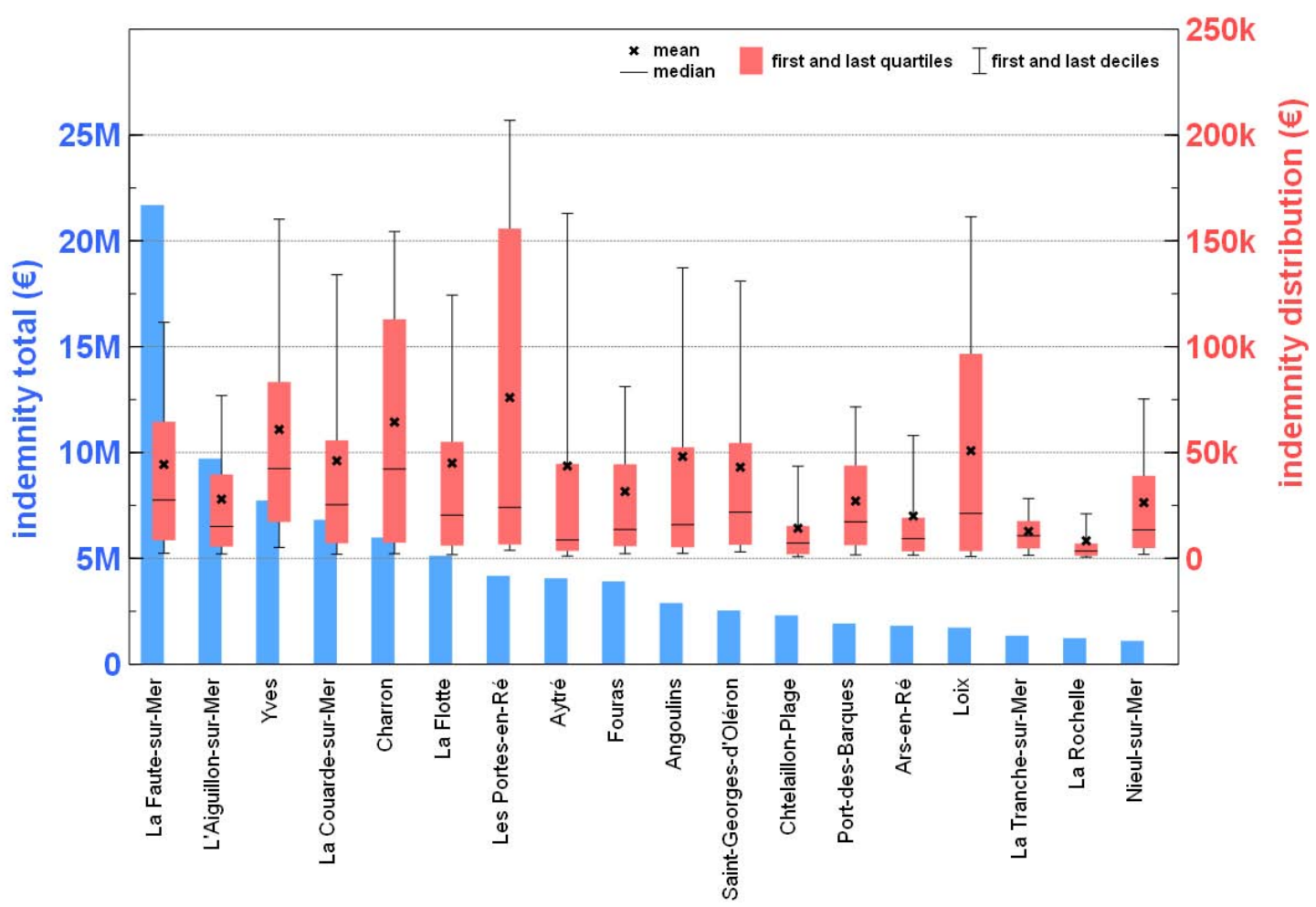

Fig. 3. Total sum of indemnities (in blue) and indemnity distribution (in red) for residential building damages, in towns having a total indemnity of at least 1 million $€$, for the three insurance companies that took part in the study. The resulting dataset is believed to represent around $25 \%$ of the overall insurance market in France.

classes that can be compared. It should be pointed out that for both events, a large majority of personal lines property damage occurred on single-family homes, collective buildings being very scarce in the flooded areas. Moreover, this damage typology was linked to the different damage processes at the building scale. Cases where the main building was affected principally involved basic flooding processes, accompanied by a significant velocity in some areas, or conversely, with water stagnating for many days, especially in the buildings with basements. Scouring of building foundations sometimes occurred but remains rare. Damage to elements outside the buildings (i.e. retaining walls and plot fences) occurred particularly on properties located on the sea-front, and mostly involved high currents and wave shocks causing ground erosion and scouring.

The damage cost distribution was analysed according to the different types of construction works affected by the flood, as shown in Fig. 4. For records of the Xynthia event for which the indemnity is under the mean value of $26600 €$, building reconstruction costs are divided between interior elements (i.e. plasterworks, woodworks, electrical and plumbing systems, decorations) for $56 \%$ and accessory buildings and outdoor elements for $36 \%$. These damages are mainly associated with records where the main building is not affected, or inundated by low water depths. On the contrary, for records for which the indemnity is above the mean value of $26600 €$, more than $75 \%$ of the costs are related to interior elements. These damages are associated with records where the main building is completely flooded and so the accessory buildings and outdoor elements represent a smaller part of the costs. In both cases, structural components (i.e. building foundations, masonry, roof structures) only account for some 1 or $2 \%$ of the overall costs. On the other hand, the replacement cost of building inventory amounts to an average of 40 to $50 \%$ of the value of the building reconstruction costs. These results confirm that current buildings are vulnerable to floods mainly because their interior elements are not water-repellent and not well adapted to floods. French construction guides that propose some solutions to build in flood plains are quite recent (METL and MEDDE, 2012) and largely not yet applied.

From this level of detail, the production of empirical damage functions was investigated for the different assets affected. Figure 5 shows a scatter plot of the amount of indemnities related to the maximum water depth, for the "main buildings" typology class of damage. It depicts the high degree of scatter displayed by the costs, which can be explained by three main findings. 

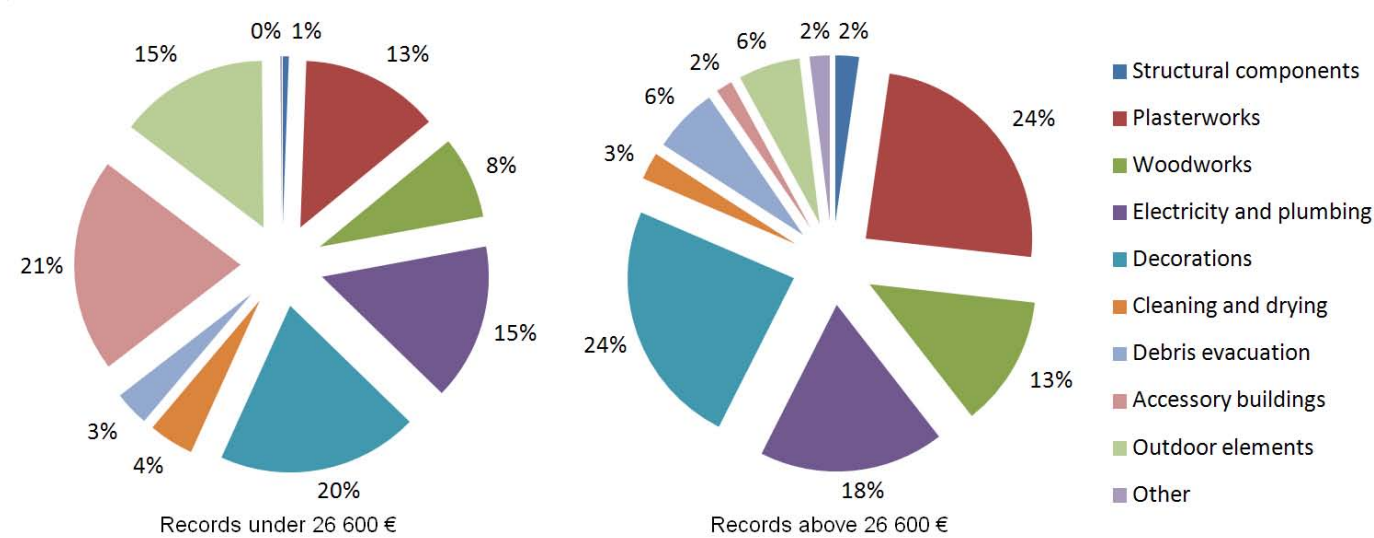

Fig. 4. Pie charts of Xynthia damage costs percentages on residential buildings, broken down according to construction elements. Records split into two groups on both sides of the mean value of $26600 €$ for housing costs.

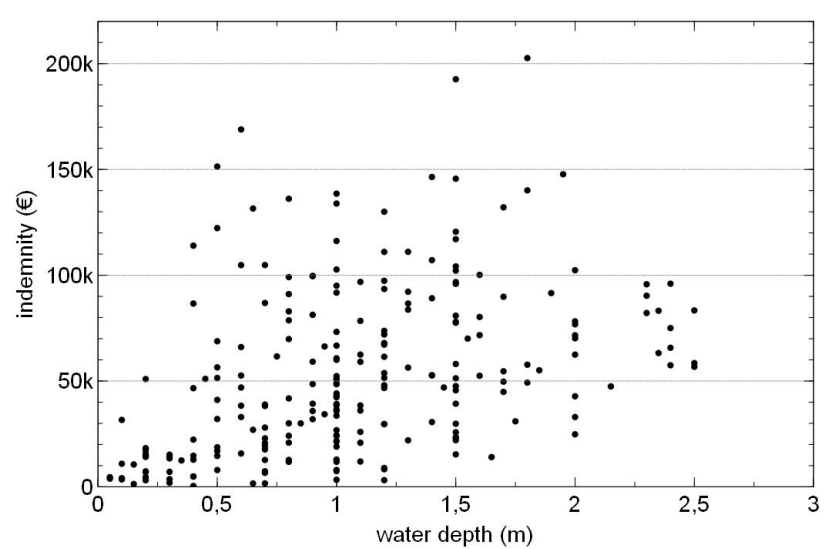

Fig. 5. Scatter plot of the Johanna and Xynthia storms records in the second-level database showing the causal relationship between indemnity for the main building and water depth.

Firstly, there is uncertainty on the water-depth measurements, and more generally on the damage circumstances indicated in loss adjustment reports. An expert's priority is to define losses and quantify the damage so it can be repaired; a precise report of the actual water depth and other hazard parameters is thus not of prime importance. Moreover, an expert must often rely on the testimony of customers when watermarks are no longer visible, or leave the information missing in the report. It should be noted that water depth is sometimes rounded off to the nearest $50 \mathrm{~cm}$ increments. Furthermore, when water depth is mentioned, the measurement reference (i.e. the ground floor of the building, or the ground outside the building) and the place in the house where the measurement was made (e.g. main rooms or basement) are often missing. These are all reasons why information on water depth is heterogeneous and lacking in precision so that the records are not always comparable with each other.
Secondly, the variability between different insurance contract terms according to items guaranteed also contributes a factor of uncertainty. Different contracts do not provide the same level of guarantees, particularly on the indemnity of the "as new" replacement cost or of the depreciated value of damaged items, when an "outdated state" threshold is reached that is evaluated by the loss adjuster. Moreover, in some contracts, some parts of the house are not covered unless the customer chooses an additional option, e.g. certain types of building inventory and outdoor elements. These points must be taken into account, bearing in mind there is currently no standard in the insurance sector in this respect. This leads to a reflection on using "as new" replacement costs or depreciated values for cost assessment purposes: the first amounts to the real compensation in most cases, while the second represents the real value of damage. Furthermore, using "as new" replacement costs is less dependent on the variability of insurance contract terms because they are based only on the expert's judgement, but it sometimes involves an improvement of some elements, between the times before and after the flood, thereby yielding an overestimation of damage.

Finally, there is significant variability in the types and characteristics of exposed buildings that defines their vulnerability and could explain disparities in damages costs, e.g. number of storeys, presence of a basement, elevation of the ground floor, and the sensitivity of the construction materials. The second type of asset parameters that could explain the replacement costs is obviously the size of the house and how its interior is fitted out; these characterise the initial construction cost of the house and hence the potential replacement cost in case of flood. 


\section{Discussion}

The study conducted underlines the input of insurance data for the Johanna and Xynthia storms, in the area of cost assessments from ex-post damage analysis. It was performed from a macro to a micro level. At the macro-scale, the first-level data available, consisting of about 4000 damage records, allowed an overall synthesis to be made of coastal flood impacts on insured assets in terms of geographic distribution and total costs (for different economic sectors of affected assets). This database is essential for sampling insurance records. However, it does not describe damage circumstances, nor hazard characteristics, and does not, in itself, allow a direct link to be established between costs and damage types. At a micro-scale, the second-level detailed information on types and costs of damage based on loss adjustment reports allowed a typology of damages and damage processes to be defined, and the costs to be divided between distinct construction works. Preliminary results show, for instance, that for events such as Johanna and Xynthia storms, the larger part of the direct costs in residential buildings are associated with interior elements, while damage to structural components is very localised and negligible.

To draw up damage functions, cost estimations were intersected with water depth for each record where the information was available. Compared with other approaches for building damage functions, such as expert judgement or field surveys (Merz et al., 2010), uncertainty remains as to developing a causal relationship between costs and hazard parameters of the flood with our insurance dataset: (i) uncertainty on water depth measurements, which are made either by loss adjusters or sometimes by the customers themselves; (ii) variability on cost assessment processes due to the different types of insurance contracts and to the lack of standardisation of methods; and (iii) the architectural characteristics of the affected building (e.g. number of floors, presence of a basement, construction method, resistance of the materials), inducing a specific vulnerability, and the size and the total initial construction cost or value of the house.

The key information cited above is very heterogeneous from one record to the next, often missing in loss adjustment reports or lacking in precision indications. These observations present, at this stage of the study, an obstacle to developing damage functions from insurance damage data alone. It demonstrates that, at this point, insurance datasets are not sufficient in themselves, and need to be reinforced by other data sources. In addition, the hazard assessment would benefit from aftermath field observations to characterise precisely the physical processes and intensity of the coastal flood. This fieldwork would also improve the characterisation and classification of the assets exposed to flooding.

To move on from an ex-post approach to an ex-ante approach for assessing potential future damage, numerical models will also be needed to provide the physical parameters (i.e. water depth, speed, hydrodynamic energy) with a high spatial resolution and precision for an object-based analysis at a micro-scale. To evaluate the vulnerability and initial value of assets, some data, in addition to that provided by insurance, can also be sought in institutional databases (e.g. national institutes of geography and statistics, land register services, taxes services); however, when available, they are often too aggregated.

Furthermore, empirical damage functions from ex-post damage assessments raise questions on spatial transferability and temporal durability: are they transferable to other regions or countries with different hazards and asset characteristics? And with the fast pace of evolution in the market of construction costs, how long might they be able to be used without being updated?

\section{Conclusions}

In this study, a detailed database (second level) of 358 cases of flooded houses had been collected. A method for data collection had been presented, which required significant interpretation work, due to the lack of harmonisation between different loss adjustment report contents. The need for precision in empirical direct damage data, and of having access to a greater number of records available in detail for statistical analysis over time and with respect to events, highlights the need for recommendations to the insurance profession about standardising data collection in the loss adjustment process (on damage surrounding circumstances, i.e. precise water depth measurements, and on typology and characteristics of exposed buildings, i.e. initial value). This should lead to improved archiving and sharing of damage records, in order to access numerical comprehensive information on a statistical level for future natural disasters, no longer needing to carry on such an analysis based on individual paper reports.

This study made it possible to obtain feedback from experience on damage caused by two coastal storms using insurance datasets, a process that should be widespread after such events, in the interests of improving flood management policies. The scarcity of ex-post flood damage data needed for building damage models is very often cited by the scientific community (Merz et al., 2010). Working with datasets from the insurance sector is a partial solution to this lack of damage information. For future events, a standardised database of insurance records could significantly contribute to the production of empirical damage functions. This objective could be achieved by consolidating partnerships between natural risks research and the insurance and reinsurance sectors, as well as the loss adjustment profession, an important source of damage data acquisition.

Procuring object-based damage functions at the microscale is an ongoing research undertaking: a number of causes of uncertainty have been mentioned which, at this stage, limit the precision of a damage prediction model, point that had also been underlined by Spekkers et al. (2011) in an 
analysis of insurance datasets about pluvial flood damage. The preliminary results are nevertheless interesting, and current analyses, still in their early stages, allow the main types of building damage to be identified, in relation to their locations and mean indemnities. In all events, complementary sources of data on hazards and asset vulnerability parameters, including field data, will definitely still be necessary for damage modelling. Further analyses will consider crossing insurance data with external material, such as more precise simulated hazard parameters, housing characteristics, socioeconomic statistical data, etc. As recently demonstrated by Merz et al. (2013), multivariate approaches can significantly improve the costs assessment model, compared to the damage function classical approach. These approaches should also be more deeply investigated.

Acknowledgements. The present work is part of the JOHANNA research project and the associated Ph.D., which are funded by the MAIF Foundation for Risk Prevention Research and the BRGM. The authors wish to acknowledge the steering committee for its involvement in framing the research, and express special thanks to the insurance companies AXA, MAAF and MAIF and the adjusting firms ELEX and Polyexpert for making us welcome and allowing us access to their data. We thank Steven Aminot for the work he conducted under his Master's degree internship. We thank the editor and two anonymous referees for their comments on an earlier version of this paper.

Edited by: R. Schwarze

Reviewed by: two anonymous referees

\section{References}

APFM (Associated Programme on Flood Management): Conducting flood loss assessments - A tool for integrated flood management, Technical document no. 7, Flood management tools series, 30 pp., available at: http://www.apfm.info/?page_id=787 (last access: December 2012), 2007.

Bertin, X., Bruneau, N., Breilh, J.-F., Fortunato, A. B., and Karpytchev, M.: Importance of wave age and resonance in storm surges: The case Xynthia, Bay of Biscay, Ocean Model., 42 1630, doi:10.1016/j.ocemod.2011.11.001, 2012.

Cariolet, J.-M., Costa, S., Caspar, R., Ardhuin, F., Magne, R., and Goasguen, G.: Atmospheric and marine aspects of the 10th of March 2008 storm in Atlantic and in the Channel, Norois, 215, 11-31, doi:10.4000/norois.3242, 2010 (in French).

Deboudt, P.: Towards coastal risk management in France, Ocean Coast. Manage., 53, 366-378, doi:10.1016/j.ocecoaman.2010.04.013, 2010.

FEMA (Federal Emergency Management Agency): Hurricane Katrina in the Gulf Coast: Mitigation Assessment Team Report, Building Performance Observations, Recommendations, and Technical Guidance, FEMA 549, available at: http://www.fema. gov/resource-document-library (last access: December 2012), 2006.

FFSA (Fédération Française des Sociétés d'Assurance) and GEMA (Groupement des Entreprises Mutuelles d'Assurance): La tempête Xynthia du 28 février 2010 - Bilan chiffré au 31 décembre 2010, 19 pp., available at: http://www.ffsa.fr/sites/ upload/docs/application/pdf/2011-06/bilanxynthia28022011.pdf (last access: December 2012), 2011 (in French).

Genovese, E. and Przyluski, V.: Storm Surge Disaster Risk Management: the Xynthia Case Study in France, J. Risk Res., 16, 7, 825-841, doi:10.1080/13669877.2012.737826, 2013.

Gerritsen, H.: What happened in 1953? The Big Flood in the Netherlands in retrospect, Philos. T. R. Soc. A., 363, 1271-1291, doi:10.1098/rsta.2005.1568, 2005.

Kelman, I. and Spence, R.: An overview of flood actions on buildings, Eng. Geol., 73, 297-309, doi:10.1016/j.enggeo.2004.01.010, 2004.

Kreibich, H., Piroth, K., Seifert, I., Maiwald, H., Kunert, U., Schwarz, J., Merz, B., and Thieken, A. H.: Is flow velocity a significant parameter in flood damage modelling?, Nat. Hazards Earth Syst. Sci., 9, 1679-1692, doi:10.5194/nhess-9-1679-2009, 2009.

Lequeux, Q. and Ciavola, P.: Methods for Estimating the Costs of Coastal Hazards, CONHAZ Project Deliverable D7.1, 67 pp., available at: http://conhaz.org/outcomes-1 (last access: December 2012), 2012.

Merz, B., Kreibich, H., Thieken, A., and Schmidtke, R.: Estimation uncertainty of direct monetary flood damage to buildings, Nat. Hazards Earth Syst. Sci., 4, 153-163, doi:10.5194/nhess-4-1532004, 2004.

Merz, B., Kreibich, H., Schwarze, R., and Thieken, A.: Review article "Assessment of economic flood damage", Nat. Hazards Earth Syst. Sci., 10, 1697-1724, doi:10.5194/nhess-10-16972010, 2010.

Merz, B., Kreibich, H., and Lall, U.: Multi-variate flood damage assessment: a tree-based data-mining approach, Nat. Hazards Earth Syst. Sci., 13, 53-64, doi:10.5194/nhess-13-53-2013, 2013.

Messner, F., Penning-Rowsell, E., Green, C., Meyer, V., Tunstall, S., and Van der Veen, A.: Evaluating flood damages: guidance and recommendations on principles and methods, FLOODsite Project Deliverable D9.1, 178 pp., available at: http://www. floodsite.net $/ \mathrm{html} /$ publications3.asp?taskID $=9$ (last access: December 2012), 2007.

METL (Ministère de l'Egalité des Territoires et du Logement) and MEDDE (Ministère de l'Ecologie, du Développement Durable, et de l'Energie): Référentiel de travaux de prevention du risque inondation dans l'habitat existant, report, 91 pp., available at: http://www.developpement-durable.gouv.fr/ Referentiel-de-travaux-de.html (last access: December 2012), 2012 (in French).

Meyer, V., Becker, B., Markantonis, V., and Schwarze, R.: Costs of Natural Hazards - A Synthesis, CONHAZ Project Deliverable D9.1, 63 pp., available at: http://conhaz.org/outcomes-1 (last access: December 2012), 2012.

Parker, D. J., Green, C. H., and Thompson, P. M.: Urban flood protection benefits: A project appraisal guide (The Red Manual), Gower Technical Press, Aldershot, 284 pp., 1987.

Pedreros, R., Garcin, M., Krien, Y., Monfort, D., Mugica, J., and François, B.: Tempête Xynthia : compte-rendu de mission préliminaire, rapport BRGM/RP-58261-FR, 43 pp., available at: http://infoterre.brgm.fr/rapports/RP-58261-FR.pdf (last access: December 2012), 2010 (in French). 
Penning-Rowsell, E., Johnson, C., Tunstall, S., Tapsell, S., Morris, J., Chatterton, J., and Green, C.: The Benefits of Flood and Coastal Risk Management: A Manual of Assessment Techniques, Middlesex Univ. Press, UK, 238 pp., 2005.

Pistrika, A. K. and Jonkman, S. N.: Damage to residential buildings due to flooding of New Orleans after hurricane Katrina, Nat. Hazards, 54, 2, 413-434, doi:10.1007/s11069-009-9476-y, 2010.

Spekkers, M. H., Ten Veldhuis, J. A. E., Kok, M., and Clemens, F. H. L. R.: Analysis of pluvial flood damage based on data from insurance companies in the Netherlands, Proceedings International Symposium Urban Flood Risk Management, UFRIM, September 21-23, Graz, Austria, 2011.

Thieken, A. H., Olschewski, A., Kreibich, H., Kobsch, S., and Merz, B.: Development and evaluation of FLEMOps - a new Flood Loss Estimation MOdel for the private sector, in: Flood Recovery, Innovation and Response edited by: Proverbs, D., Brebbia, C. A., and Penning-Rowsell, E., WIT Press, 315-324, doi:10.2495/friar080301, 2008.
Thourot, P.: Dans la tempête médiatique, Risques, Les cahiers de l'assurance, 91, available at: http://www.ffsa.fr/webffsa/risques. nsf/html/Risques_91_0008.htm (last access: December 2012), 2012 (in French).

Torterotot, J.-P.: Cost of damage due to river flooding: assessment and uncertainty analysis, Ph.D. thesis, Ecole Nationale des Ponts et Chaussées, France, 284 pp., available at: http://tel. archives-ouvertes.fr/tel-00421862 (last access: December 2012), 1993 (in French).

Vinet, F., Defossez, S., Rey, T., and Boissier, L.: The production process of flooding risk in coastal area: the example of "Xynthia" areas, Norois, 222, 11-26, doi:10.4000/norois.3834, 2012 (in French). 